\title{
A nanogold supported inorganic/organic hybrid 3D sensor for electrochemical quantification of propranolol-effective antagonist of $\beta$-adrenergic receptors
}

\author{
T. Łuczak $^{1}$
}

Received: 11 February 2019 /Revised: 5 June 2019 / Accepted: 6 June 2019 / Published online: 24 June 2019

(C) The Author(s) 2019

\begin{abstract}
The new hybrid inorganic/organic 3D nanogold electrode material composed of gold template, gold nanoparticles, 4mercaptobutyric acid, and cysteamine has been prepared and for the first time used for electrochemical oxidation and quantitative determination of propranolol, an effective antagonist of $\beta$-adrenergic receptors, in the buffered solution and in the simulated body fluids. A high improvement in electrooxidation of propranolol as compared to that observed on the unmodified gold was detected. The prepared sensor was found to give reliable results in the propranolol concentration range between 0.0001 and $0.02 \mathrm{mM}$ with the detection limit of $6.75 \times 10^{-5} \mathrm{mM}$ without any interference from biogenic species. A new inorganic/organic hybrid 3D nanogold sensor displays good sensitivity, repeatability, and stability which make it a promising tool for application both in clinical diagnosis and pharmaceutical analysis.
\end{abstract}

Keywords Nanogold hybrid material $\cdot$ Self-assembled layer $\cdot$ Voltammetric sensor $\cdot \beta$-Adrenergic receptors blocking drug

\section{Introduction}

One of a commonly known and used of $\beta$-blocking drugs is propranolol (PROP) - an effective antagonist of $\beta$-adrenergic receptors. Indications for the use of propranolol include, among others, hypertension, angina pectoris, and cardiac arrhythmia, as well as prophylaxis of myocardial infarction. This drug also effectively eliminates some of the symptoms of neurosis and anxiety attacks. It may also support the treatment of hyperthyroidism. Moreover, it is also used as a remedy for various types of headaches, including migraine pain [1-4]. As a non-selective $\beta$-blocker, propranolol can be used to counteract overproduction of catechol amines: adrenaline and noradrenaline. It is often used to alleviate the trauma of

Electronic supplementary material The online version of this article (https://doi.org/10.1007/s11581-019-03113-2) contains supplementary material, which is available to authorized users.

T. Łuczak

telucz@amu.edu.pl

1 Faculty of Chemistry, Adam Mickiewicz University in Poznań, Uniwersytetu Poznańskiego 8, 61-614 Poznan, Poland alcohol and drug withdrawal, as well as to relieve the stress associated with stressful events such as exam and public speech $[5,6]$. Propranolol has been introduced on the list of prohibited drugs by the World Anti-Doping Agency (www. wada-ama.org/sites/default/files/prohibited_list_2018_en. pdf). Unfortunately, propranolol, like many other drugs, can cause serious side effects. Among them, one should mention: bradycardia, worsening of heart failure, hypotension, peripheral circulation disorder, feeling of bewilderment, mood changes, dizziness, nightmares, hallucinations, and even psychosis [4]. As described above, propranolol may be used for treatment of a wide spectrum of ailments; therefore, it can be easily overdosed. For this reason, the design of different methods for its detection and determination is an important challenge for scientific study. Different techniques have been proposed for the determination of propranolol, such as spectrophotometry [7-15], chemiluminescence [16-18], chromatography [19-21], colorimetry [22], and titrimetry $[23,24]$. Although all these methods display good precision and accuracy, meanwhile from the analytical point of view, some of these methods are complex-have required several preparatory steps prior to testing, are time-consuming, and usually needed using toxic solvents. Literature provides evidences that propranolol has an electroactive nature [25], so it 
can be determined electrochemically. This fact is particularly important from an analytical point of view because electroanalytical methods have some important advantages over the methods mentioned above for quantification of propranolol. There is no doubt that these advantages include good selectivity, low detection limit, excellent reproducibility, high stability, rapid response, and simple operating procedures. Moreover, electroanalytical methods are environmental friendly and have relatively low costs of analysis [26]. Literature provides evidences of using electroanalytical methods for propranolol quantification in practice. However, the amount of information on electrochemical behavior of this drug is still rather scarce. The first studies have been made on unmodified electrodes: carbon paste and carbon nanotubes paste electrodes, mercury, platinum, and gold [27-30]. Moreover, a boron-doped diamond electrode has been used for propranolol detection [31]. Nowadays, it has been proved that better results during propranolol oxidation are obtained on modified electrodes; for instance, literature reports on the use of multi-wallet carbon nanotube/silicone rubber composite and calixarene/multi-wallet carbon nanotubes modified glassy carbon electrodes [32-34]. Propranolol electrochemical was studied also at the glassy carbon electrode modified with multi-walled carbon nanotubes doped with platinum nanoparticles $[35,36]$. For the same purpose, the functionalized multiwalled carbon nanotubes within a poly (allylamine hydrochloride) film has been used [37]. Moreover, a carbon paste electrode based on $\gamma$-cyclodextrin-carbon nanotube composite ( $\gamma$-CD-CNT-CME) was developed for the determination of propranolol hydrochloride [38]. It was found that a nitrogencontaining tetrahedral amorphous carbon electrode can be an excellent new carbon material for electrochemical propranolol detection [39]. Some information on propranolol electrochemical can be get when using both the edge plane pyrolytic graphite (EPPG) electrode modified both with poly-(melamine) film [40] and the graphene and conductive polymer (poly-1,5-diaminonaphthalene) [41]. The electrochemical behavior of propranolol has been also analyzed at a graphite screen printed electrode modified with zirconium dioxide [42]. Very recently, the glassy carbon electrode modified both with functionalized graphene, ionic liquid, and silver nanoparticles for detection propranolol has been tested [43].

The way of modification of some of mentioned above electrodes is complicated and needs toxic and expensive modifying compounds and/or solutions. To avoid this, scientists are still looking for new modified electrode materials that could be obtained in a simple, fast, cheap, and green way. From literature, it is known that gold nanoparticles significantly enhance the catalytic properties of conducting materials of electrodes [44]. Following this idea, based on a preliminary result found in literature indicating that gold may be a good catalyst for propranolol electrooxidation [30], the goal of the present study was fabrication of a new inorganic/organic hybrid 3D nanogold sensor modified with the self-assembled layer (SAM) for electrochemical oxidation and quantification of propranolol in buffered solution at $\mathrm{pH}$ close to physiological one. Moreover, the quantification of propranolol pharmaceutical formulation dissolved in the simulated body fluid (SBF) will be checked. Such studies have not been so far reported in literature. The results are very important both in pharmaceutical analysis and clinical diagnosis.

\section{Experimental}

\section{Apparatus}

The following apparatus were used: Autolab potentiostat/ galvanostat analyzer (AUTOLAB PGSTAT 302N); the $\mathrm{pH}$ meter (Model-ULAB 2002); a UV-Vis spectrometer; a Brucker $66 \mathrm{v} / \mathrm{S}$ FT-IR spectrometer; the transmission electron microscopy (JEM - 1200 EX2); the scanning electron microscopy (ZEISS EVO 40 instrument). Water purification system TKA MicroPure.

\section{Reagents}

All reagents used in the measurements were of high purity and were used as received without their further purification. $\mathrm{HCl}$, $\mathrm{KCl}, \mathrm{NaCl}, \mathrm{NaOH}, \mathrm{KNO}_{3}, \mathrm{H}_{2} \mathrm{SO}_{4}, \mathrm{H}_{2} \mathrm{O}_{2}, \mathrm{~K}_{3}\left[\mathrm{Fe}(\mathrm{CN})_{6}\right]$, $\mathrm{K}_{4}\left[\mathrm{Fe}(\mathrm{CN})_{6}\right] \cdot 3 \mathrm{H}_{2} \mathrm{O}, \mathrm{KH}_{2} \mathrm{PO}_{4}, \mathrm{Na}_{2} \mathrm{HPO}_{4} \cdot 2 \mathrm{H}_{2} \mathrm{O}, \mathrm{NaH}_{2} \mathrm{PO}_{4}$. $\mathrm{H}_{2} \mathrm{O}, \mathrm{NaHCO}_{3}, \mathrm{CaCl}_{2}, \mathrm{MgSO}_{4} \cdot 7 \mathrm{H}_{2} \mathrm{O}$, trisodium citrate, acetone, and ethyl alcohol were from POCh-Gliwice, buffer solutions of $\mathrm{pH}$ : from 1 to 11 were from VWR-Poland. Auric acid, 4-mercaptobutyric acid, cysteamine, and propranolol (tris(hydroxymethyl)aminomethane), ascorbic acid, uric acid, and dopamine were purchased from Sigma-Aldrich. Propranolol WZF tablets (1 tablet contain $40 \mathrm{mg}$ of propranolol) and propranolol solution for injection (1 ampoule containing $1 \mathrm{mg}$ of propranolol per $1 \mathrm{ml}$ ) were obtained from Polfa, Warsaw, Poland.

\section{Solutions}

All solution used were prepared with ultra-pure deionized water with conductivity of $0.055 \mu \mathrm{S}$. As a supporting electrolyte solution, $0.07 \mathrm{mM}$ phosphate buffer of $\mathrm{pH} 7.4$ was used. Before the analysis, all the laboratory glasses had been washed with the Piranha solution (persulfuric acid - Caro acid). Piranha solution is a mixture of concentrated sulfuric acid (VI) and 30\% hydrogen peroxide prepared in the ratio $3 v /$ $v: 1 v / v$ under the fume hood. The Au colloidal solution (Au sol) was prepared according procedure described elsewhere, [45]. The simulated body fluid (SBF) was prepared according to Kokubo's procedure by dissolving in deionized water appropriate amounts of different compounds (mentioned above) 
to obtain a solution in which the concentration of $\mathrm{Na}^{+}, \mathrm{K}^{+}$, $\mathrm{Ca}^{2+}, \mathrm{Cl}^{-}, \mathrm{HCO}_{3}{ }^{-}, \mathrm{HPO}_{4}{ }^{2-}, \mathrm{SO}_{4}{ }^{2-}$ ions will be $142 \mathrm{mM}$, $5 \mathrm{mM}, 2.3 \mathrm{mM}, 103 \mathrm{mM}, 27 \mathrm{mM}, 1 \mathrm{mM}$, and $0.5 \mathrm{mM}$, respectively. The above mentioned concentrations of each ion are the same as those in human blood plasma maintained under identical physiological $\mathrm{pH}$ conditions [46].

To prepare the real samples with propranolol to analysis, 8 tablets of propranolol WZF (each containing $40 \mathrm{mg}$ of the drug) were accurately triturated in a mortar. Next $0.2593 \mathrm{~g}$ of triturated drug was transferred up to volumetric flask c.a. $1000 \mathrm{~cm}^{3}$ and dissolved in SBF. In obtained solution, the propranolol concentration was equal to $1 \mathrm{mM}$. To obtain different exact propranolol concentrations, different volumes of the prepared solution were dissolved in SBF. Moreover, the real samples with propranolol for analysis were prepared using the propranolol solution for injection. For this purpose, the content of 1 ampoule containing $1 \mathrm{mg} \mathrm{cm}^{-3}$ of propranolol was dissolved quantitatively in $100 \mathrm{~cm}^{3}$ of SBF. In the latter solutions, the propranolol concentration was equal to $3.86 \times$ $10^{-2} \mathrm{mM}$. For analysis, $10 \mathrm{~cm}^{3}$ of this solution was taken. For interference studies, the analytical standard solutions of dopamine $\left(1 \mathrm{mM}, 10 \mathrm{~cm}^{3}\right)$, ascorbic acid $\left(50 \mathrm{mM}, 10 \mathrm{~cm}^{3}\right)$, and uric acid $\left(50 \mathrm{mM}, 10 \mathrm{~cm}^{3}\right)$ were quantitatively put into $100 \mathrm{~cm}^{3}$ volumetric flasks and were dissolved to the volume of $100 \mathrm{~cm}^{3}$ with SBF. The obtained concentrations of dopamine, ascorbic acid, and uric acid were $0.1 \mathrm{mM}, 5 \mathrm{mM}$, and $5 \mathrm{mM}$, respectively. The mixture of four compounds was prepared as follows: $1 \mathrm{~cm}^{3}$ of $0.1 \mathrm{mM}$ solution of propranolol, $1 \mathrm{~cm}^{3}$ of $0.1 \mathrm{mM}$ solution of dopamine, $1 \mathrm{~cm}^{3}$ of $5 \mathrm{mM}$ solution of uric acid, and $1 \mathrm{~cm}^{3}$ of $5 \mathrm{mM}$ solution of ascorbic acid were put into a $100 \mathrm{~cm}^{3}$ volumetric flask and dissolved up to this volume with SBF. At the end in such prepared mixture, the concentrations of propranolol, dopamine, uric acid, and ascorbic acid were $1 \times 10^{-3} \mathrm{mM}, 1 \times 10^{-3} \mathrm{mM}, 5 \times$ $10^{-2} \mathrm{mM}$, and $5 \times 10^{-2} \mathrm{mM}$, respectively.

\section{Electrodes}

In this study, either unmodified or modified polycrystalline gold $(\mathrm{Au})$ was used as working electrode. Geometrical areas of the electrodes were evaluated from the Randles-Sevčik equation [26] as $0.064 \mathrm{~cm}^{2}$ and $0.115 \mathrm{~cm}^{2}$, respectively. A polycrystalline gold electrode with a much larger surface area as compared to that of working electrode and a saturated calomel electrode (SCE) were used as a counter and reference electrode, respectively. The unmodified and modified electrodes before use were washed with the Piranha solution, rinsed with distilled and deionized water. The SCE electrode was only rinsed with distilled and deionized water. Then dry electrodes were located into clean the three-compartment electrochemical cell separated by glass frits which was used in electrochemical measurements. Electrochemical activation of the bare polycrystalline gold electrode was carried out as described earlier [47]. All measurements described were made at room temperature using solutions deoxygenated by $99.998 \%$ argon. Between measurements, the rinsed and dry unmodified or modified gold electrodes were stored in an empty tube.

In order to obtain the hybrid inorganic/organic nanogold modified Au electrode (labeled as 3D-Au-NPs-Au), the activated polycrystalline bare $\mathrm{Au}$ electrode (labeled as 2D Au) was submerged in the following solutions: Au sol (NPs-Au), $0.01 \mathrm{M}$ alcoholic solution of 4-mercaptobutyric acid (MBA), $0.005 \mathrm{M}$ solution of cysteamine (CA), and once again in $\mathrm{Au}$ sol solution. After each modification step, the modified template was rinsed and dried. The exact time of immersion of modified template in each modifying solution was determined in preliminary tests and established as $10 \mathrm{~h}, 4 \mathrm{~h}, 2 \mathrm{~h}$, and once again $10 \mathrm{~h}$ in the Au sol solution, in the MBA solution, in the CA solution, and second time in the Au sol solution, respectively. It should be noticed that after each modified template immersion in a given modifying agent [Au-NPs, MBA, CA, and once again Au-NPs], a new modified electrode was obtained. In all of these studies, 4 modified electrodes were prepared: 3D-Au-NPs, 3D-Au-NPs-MBA, 3D-Au-NPsMBA-CA, and 3D-Au-NPs-MBA-CA-Au-NPs. For TEM, UV-vis, and FT-IR characterization of the modified agent used in this paper, see the electronic supporting information Fig. S1. Moreover, Fig. S2 (the electronic supplementary material) schematically presents the four-step modification path from 2D Au electrode to 3D Au-NPs-Au electrode.

Four obtained electrodes were tested in the preliminary measurements and it was concluded that the highest catalytic effect was obtained when the 3D-Au-NPs-MBA-CA-Au-NPs electrode was used as a working electrode. For this reason, the detailed electrochemical studies of propranolol were made only on this electrode. For the sake of clarification, the unmodified (2D Au electrode) and modified (3D Au-NPs-MBACA-Au-NPs electrode) electrodes were labeled as 2D Au and $3 \mathrm{D} \mathrm{Au-NPs-Au,} \mathrm{respectively,} \mathrm{and} \mathrm{such} \mathrm{acronyms} \mathrm{will} \mathrm{be} \mathrm{used}$ in the text below.

\section{Results and discussion}

\section{Characterization of the modified electrode}

The subsequent stages of modification of the 2D Au electrode, which lead to obtaining the 3D Au-NPs-Au electrode, are shown schematically in Fig. S2. A gold nanoparticle modified gold template was obtained without binder molecules [48]. It means that the activated Au electrode (2D Au electrode) was directly dipped in colloidal gold solution. The Au-NPs layer was formed making use of the electrostatic interactions between the gold nanoparticles stabilized with citrate anions, used in the present study, which are endowed with negative 
charge [49]. The surface obtained was called threedimensional (3D) Au electrode and labeled as 3D Au-NPs. It is generally accepted in literature that chemisorption of alkane thiols and other S-functionalized aliphatic compounds on gold is preceded by the oxidative abstraction of hydrogen from S-H bonds, whereas the organic molecules existing in the trans-conformation in solution transform into an ordered structure with alkane chains oriented at a tilt angle of $20^{\circ}-30^{\circ}$ toward the electrode surface $[50,51]$. Per analogy to the SAM formation of alkane thiols on a gold substrate [52-54], the firm attachment of MBA acid to the 3D Au-NPs template surface was realized via developing the covalent bonds between $\mathrm{Au}-\mathrm{NPs}$ nanoparticles and $\mathrm{S}$ atoms after $\mathrm{S}-\mathrm{H}$ bond has been split in the MBA acid molecule. As a consequence, the 3D Au-NPs-MBA template was formed. The $\mathrm{COOH}$ terminated layers of MBA attached to the gold nanoparticles surface can be easily bonded with the amine group of cysteamine when such a modified electrode comes in contact with a solution of the latter compound. By comparison of the $\mathrm{p} K_{\mathrm{a}}$ values of MBA ( $K_{\mathrm{a}}=3.7$ (www.Reaxys.com)) and $\mathrm{pKa}$ of cysteamine ( $p K_{\mathrm{a}} 8.35$ and 10.81) (www.Reaxys.com), it is obvious that the carboxylic groups of MBA are mostly dissociated at $\mathrm{pH}=7.4$ of the electrolyte solution and the $\mathrm{COO}^{-}$terminated negatively charged layers $\mathrm{COO}^{-}$of MBA can favorably interact with protonated $\mathrm{NH}_{3}{ }^{+}$group (i.e., the positively charged part CA). Moreover, strong hydrogen bonds may be formed between carboxylic groups of the acid and the amine group of cysteamine [25]. This explains development of a stable MBA-CA connection exposed with the SH group of cysteamine directed toward the top-side of the monolayer formed. As a result, the $\mathrm{Au} / \mathrm{Au}-\mathrm{NPs} / \mathrm{MBA} / \mathrm{CA}$ template was developed. Consequently, it is possible to modify further the $\mathrm{Au} / \mathrm{Au}-\mathrm{NPs} / \mathrm{MBA} / \mathrm{CA}$ electrodes with gold nanoparticles, via formation of the covalent bonds between $\mathrm{S}$ atoms of CA and Au-NPs. In this way, the Au/Au-NPs/ $\mathrm{MBA} / \mathrm{CA} / \mathrm{Au}-\mathrm{NP}-\mathrm{s}$ electrode (labeled as 3D Au-NPs-Au) with gold nanoparticles on top of the created SAM layer was obtained. As previously reported $[55,56]$, the sulfurfunctionalized aliphatic carboxylic acids form wellorganized two-dimensional compact monolayers on the bare gold electrode (2D Au), whereas the three-dimensional SAMs developing on $\mathrm{Au}$ electrodes (2D template) coated with $\mathrm{Au}$ nanoparticles (3D template) exhibit a more disordered structure. This opinion is supported by the observation that permeability of SAMs increases with increasing substrate roughness [57] which was confirmed by IRRAS spectra [58] from which it appears that the permeability of self-assembled layers increases at surfaces with higher levels of roughness [52, 57].

An electrochemical picture of unmodified and modified electrode is presented in Fig. 1 in the form respective cyclic voltammograms. From electrochemical literature [26], it is clear that due to the electrode modification, its roughness factor $r f=A_{\mathrm{r}} / A_{\mathrm{g}}$ (where $r f$ is the electrode roughness factor, while $A_{\mathrm{r}}$ and $A_{\mathrm{g}}$ are

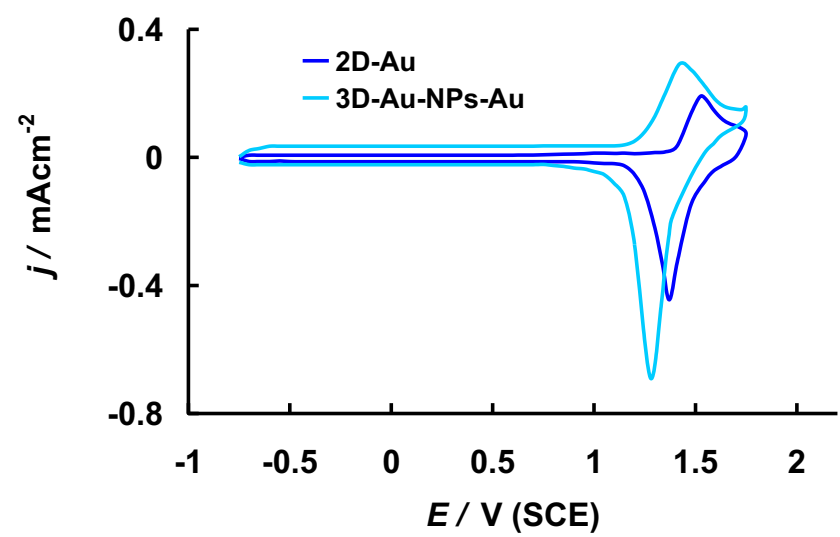

Fig. 1 Cyclic voltammograms recorded on unmodified (2D $\mathrm{Au}$ ) and modified (3D Au-NPs-Au) electrodes in phosphate buffer, pH 7.4. $v=$ $0.1 \mathrm{Vs}^{-1}$

the real and geometrical area of electrode, respectively) increases. Thus, the increase in $r f$ results in increasing of the real electrochemical electrode surface area. Taking into account the fact that the reduction of $1 \mathrm{~cm}^{2}$ of the oxide film adsorbed on the gold electrode surface requires the charge flow of $0.4 \mathrm{mC} / \mathrm{cm}^{2}$ through it [59], the calculated $r f$ for the 2D Au and 3D Au-NPs-Au electrodes tested in this paper were 1.89 and 2.41 , respectively. The fact that the roughness factor increases after 2D Au electrode modification is confirmed by the SEM images obtained, shown in Fig. 2. By taking into account the obtained $r f$ values, the real electrochemical areas of the tested electrodes were calculated [26] as $0.12 \mathrm{~cm}^{2}$ for 2D Au electrode and $0.28 \mathrm{~cm}^{2}$ for 3D AuNPs-Au.

\section{Oxidation of propranolol at unmodified and modified gold electrodes}

Electrooxidation of propranolol both at unmodified (the 2D $\mathrm{Au}$ ) and modified gold electrode (3D-Au-NPs-Au) is reflected as a single irreversible peak visible in respective cyclic voltammograms (CV) (Fig. 3). For comparison, the CVs recorded at the 2D Au and 3D Au-NPs-Au electrode in the pure supporting electrolyte solution $(0.07 \mathrm{mM}$ phosphate buffer, $\mathrm{pH}$ 7.4) are presented too. According to general rules adopted in literature [25, 60], the irreversible peak visible in the CVs recorded is assigned to the oxidation of $\mathrm{OH}$ group in propranolol molecule to $\mathrm{C}=\mathrm{O}$ as a result of exchange of both 2 electrons and 2 protons between the propranolol molecule and the electrode surface giving 1-(isopropylamino)-3-(naphthalen-1yloxy) propan-2-one as the product of oxidation. The peak assigned to the irreversible propranolol oxidation to its ketoform on the unmodified gold electrode $(2 \mathrm{D} \mathrm{Au}$ ) begins to grow at $E=1.0 \mathrm{~V}$ vs SCE and reaches the maximum of $E=$ $1.39 \mathrm{~V}$ vs SCE with the maximum peak current density $j=$ $0.5 \mathrm{~mA} \mathrm{~cm}^{-2}$ (Fig. 3). According to the theory of electrochemical kinetics, the increase in current density and decrease in the overpotential of oxidized species should be taken into account 
Fig. 2 SEM images of a 2D Au and $\mathbf{b} 3 \mathrm{D}$ Au-NPs-Au surfaces. Scale bar $2 \mathrm{~mm}$, accelerating voltage: $20 \mathrm{kV}$; magnification $\times 10000$ a) 2D-Au

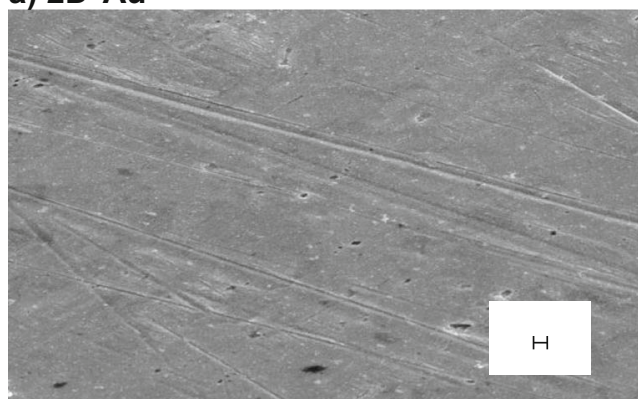

b) 3D-Au-NPs-Au

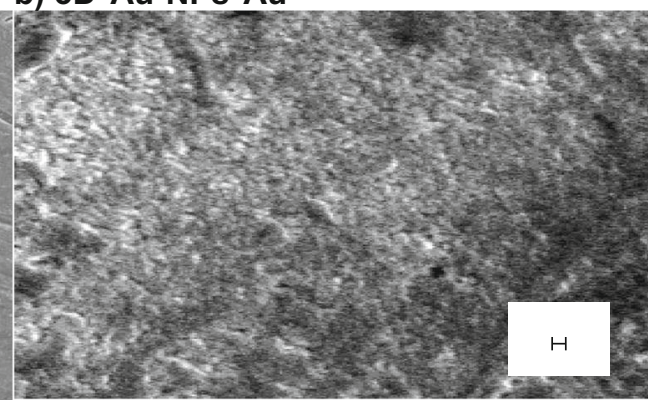

in evaluation of the electrocatalytic effect. For the modified 3D Au-NPs-Au electrode, the anodic peak begins to grow up at $E=0.65 \mathrm{~V}$ vs SCE and reaches the maximum of $E=1.24 \mathrm{~V}$ vs SCE with the maximum peak current density $j=$ $1.58 \mathrm{~mA} \mathrm{~cm}^{-2}$ (Fig. 3). Without doubt, the observed experimental data confirm that at the modified 3D Au-NPs-Au electrode, a high catalytic effect during propranolol oxidation is achieved. It is manifested both as a substantial shift in the voltammetric peak toward the negative potential values and a high increase in the current density response at this peak. One can add that during the experiment described in this work, the fouling effect on the electrode surface during propranolol oxidation was not observed, the current densities were not changed after a number of scans. If the current densities altered after successive cycles, it would indicate poisoning of the electrode surface. It should be underlined that such a high catalytic effect at the modified electrode cannot be associated only with increase in the surface area after the modification process. Taking into consideration the ratio of the real surface area of the modified and unmodified electrodes $\left(0.28 \mathrm{~cm}^{2} / 0.12 \mathrm{~cm}^{2}=2.33\right)$, the current density observed during propranolol oxidation at the 3D Au-NPs-Au electrode should be 2.33 times higher than that observed at the unmodified 2D Au electrode. While at the 3D Au-NPs-Au electrode, $j$ grows up to $1.58 \mathrm{~mA} \mathrm{~cm}^{-2}$ (Fig. 3) and it is 3.16 times higher than expected only on the basis of the increase in the real area

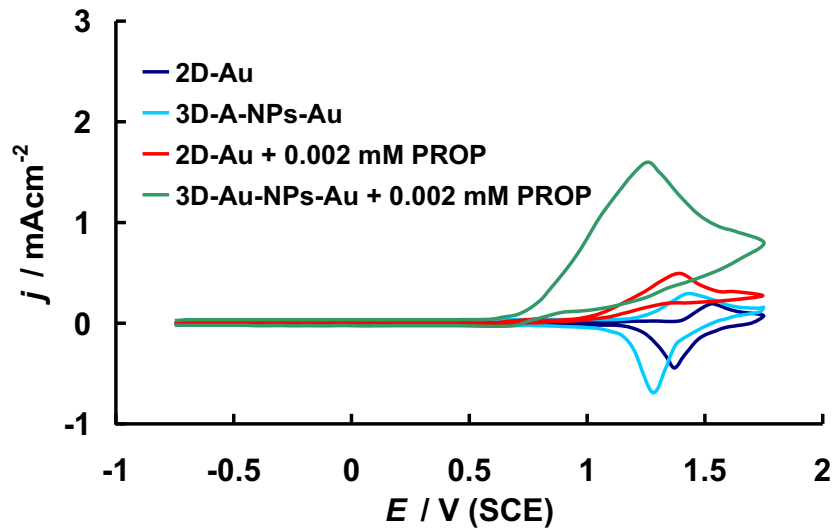

Fig. 3 Cyclic voltammograms recorded in $0.07 \mathrm{mM}$ phosphate buffer, $\mathrm{pH}=7.4$ at the $2 \mathrm{D} \mathrm{Au}$ electrode and at the 3D Au-NPs-Au without and with addition of $0.002 \mathrm{mM}$ propranolol. $v=0.1 \mathrm{~V} \mathrm{~s}^{-1}$ due to modification. The latter value shows that the obtained electrocatalytic effect observed during propranolol oxidation on the 3D Au-NPs-Au electrode depends not only on the increase in the roughness factor (and thus the real area of the electrode surface as a result of its modification with hybrid inorganic/organic material) but also other factors have impact on the rate electron transfer between oxidized propranolol and the 3D Au-NPs-Au surface. There is no doubt that architecture of the prepared SAM layer with the gold nanoparticles immobilized on the outer side of the SAM layers attached to the gold surface effectively protects the electrode metal surface from adsorption of reaction products which may poison the $3 \mathrm{D} \mathrm{Au} / \mathrm{Au}-\mathrm{NPs} / \mathrm{Au}$ electrode surface. On the other hand, this facilitates accumulation of the substance studied at the electrode/solution interface which has to permit easier penetration of the reactant through the alkane chains to the $3 \mathrm{D} \mathrm{Au} /$ $\mathrm{Au}-\mathrm{NPs} / \mathrm{Au}$ surface as compared to that at the 2D electrode and can efficiently promote tunneling of electrons between propranolol and the electrode surface [52, 57, 58]. In summary, there is no doubt that the huge electrocatalytic effect observed during propranolol electrooxidation on $3 \mathrm{D} \mathrm{Au}-\mathrm{NPs}-\mathrm{Au}$ electrode is affect both by the type and structure of the modifying SAM layer which as follows from the electrochemical aspects of catalysis decreases the energy barrier for oxidative electron transfer [26, 61].

\section{The effect of $\mathrm{pH}$}

In order to confirm the above described electrochemical behavior of propranolol on the 3D Au-NPs-Au electrode, the effect of the peak potential and the peak current density was studied by cyclic voltammetry in solutions containing $0.002 \mathrm{mM}$ of propranolol of $\mathrm{pH}$ changed in the range 1-11 (Fig. 4). With increasing $\mathrm{pH}$ of the solution, as shown in Fig. 4 $\mathrm{a}, \mathrm{b}$, the propranolol electrooxidation peak potential shifts toward negative values and the shift can be described by the following equation: $E_{\mathrm{p}}=1.64-0.060 \pm 0.02 \mathrm{pH}\left(R^{2}=0.994\right)$. The value 0.060 of the $\mathrm{d} E_{\mathrm{p}} / \mathrm{dpH}$ slope indicates that in the oxidation of propranolol at the $3 \mathrm{D} \mathrm{Au} / \mathrm{Au}-\mathrm{NPs}$ electrode the same number of electrons and protons is exchanged. This is in agreement with the electrochemical kinetics theory [26] and 
a)

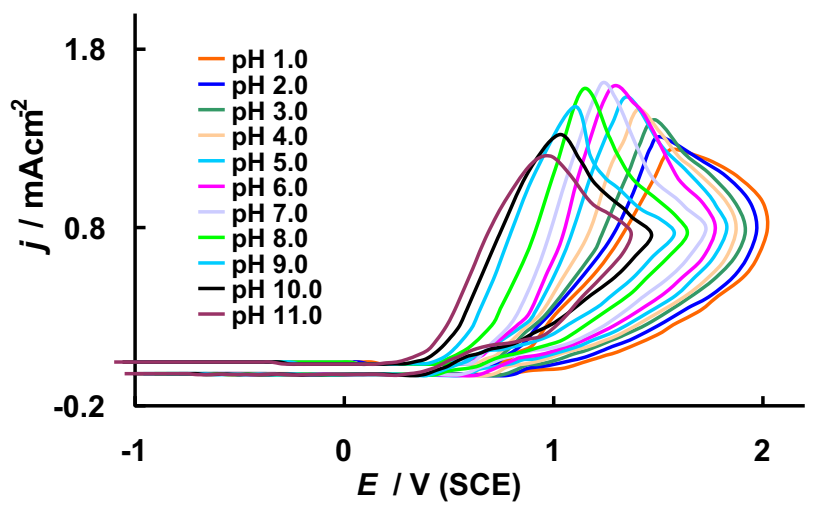

b)

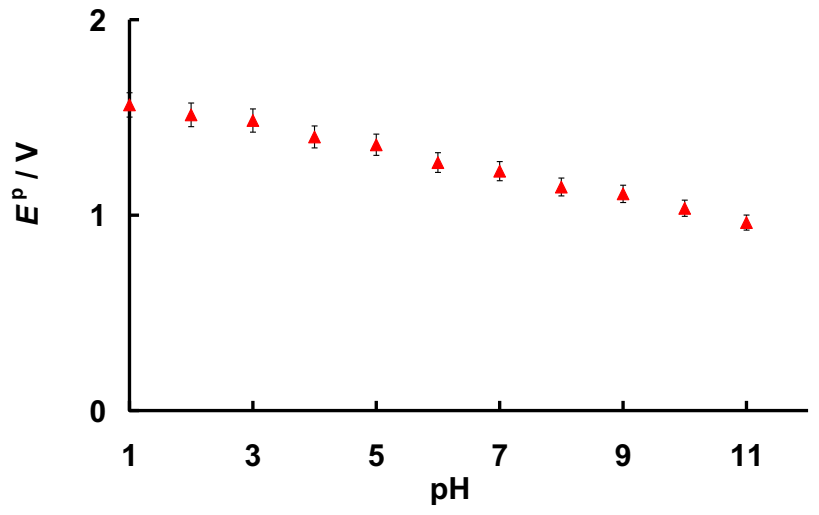

c)

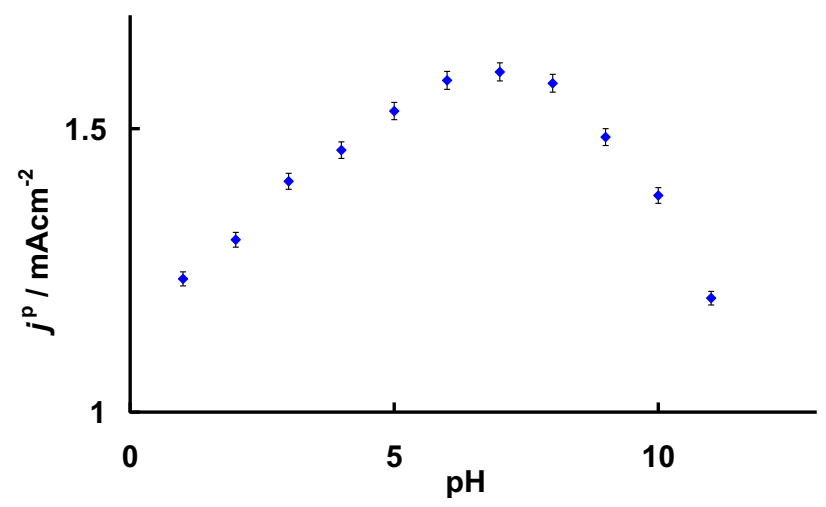

Fig. 4 a Cyclic voltammetric responses of 3D Au-NPs-Au in phosphate buffer at different $\mathrm{pH}$ containing of $0.002 \mathrm{mM}$ propranolol. $v=0.1$. b Dependence of $\mathrm{pH}$ on the current peak potential for $0.002 \mathrm{mM}$ propranolol. c Dependence of $\mathrm{pH}$ on the current peak density for $0.002 \mathrm{mM}$ propranolol

confirms the above adopted mechanism of propranolol electrooxidation. Furthermore, as shown in Fig. $4 \mathrm{c}$, the $j^{\mathrm{p}}$ of propranolol oxidation increases up to $\mathrm{pH}$ about 7-8, then a decrease in the recorded $j^{\mathrm{p}}$ values is seen. This observation may be associated with instability of propranolol at acidic condition. At low $\mathrm{pH}$, isoropyl amino side chain of propranolol can be oxidized. Gradual decreases in the peak currents in
pH range above 8 may be attribute to the deprotonation of propranolol molecules and thus cannot be effectively accumulated at the electrode surface, which leads to observed decrease in current density. The similar observation has been reported earlier [36]. The latter observation was the reason why $\mathrm{pH} 7.4$ (equal to the $\mathrm{pH}$ value of physiological condition) was chosen for further studies of propranolol on prepared 3D $\mathrm{Au}-\mathrm{NPs}-\mathrm{Au}$ electrosensor.

\section{Effect of scan rate}

The dependence of the potential scan rate on the peak potential value provides some important kinetic information. The peak potential $\left(E^{\mathrm{p}}\right)$ which is independent of the scan rate indicates a reversible charge transport process, whereas the irreversible charge transfer process causes the peak potential to vary with the potential scan rate. From the kinetics theory [26], it follows that when an increase in the scan potential rate is accompanied by an increase in the peak current density and moreover when at the same time the peak potential shifts toward more positive value, the electrochemical process is completely irreversible. The effect of scan rate on the electrooxidation of propranolol in phosphate buffer, $\mathrm{pH} 7.4$ on 3D Au-NPs-Au electrode, is shown in Fig. 5a. As follows from the recorded CVs, the $E_{\mathrm{p}}$ value increases with increasing potential scan rate, confirming that propranolol oxidation at the 3D Au-NPs-Au electrode is an irreversible process. Moreover, Fig. $5 \mathrm{~b}$ presents the variation of peak current density with the square root of the potential scan rate. The increase in the scan rates from 0.001 to $0.2 \mathrm{Vs}^{-1}$ causes an increase in the peak current density. Moreover, it was found that peak current density $\left(j^{\mathrm{p}}\right)$ showed a good linear correlation with the square root of the scan rates. This result confirmed that the considered process at the tested electrode is controlled by diffusion. This conclusion is additionally supported by the value of $\mathrm{d} \log j^{\mathrm{p}} / \mathrm{d} \log v$ slope obtained from the linear relation $d \log j{ }^{\mathrm{p}}$ vs dlogv (Fig. 5c). From the regression equation: $d \log j{ }^{\mathrm{p}}$ $(\mathrm{mA})=0.710+0.501 \mathrm{~d} \log v\left(\mathrm{Vs}^{-1}\right) ;\left(R^{2}=0.9985 ; n=17\right)$, it is seen that the value of the $d \log j / \mathrm{p} / \log v$ is very close to 0.5 , which proves that the propranolol oxidation at the $3 \mathrm{D} \mathrm{Au}-$ NPs-Au electrode is indeed diffusion controlled, which means that during the considered process, the diffusion of propranolol is slower than both its adsorption and the following electron transfer between electrooxidized substrate molecule and the electrode surface [26].

\section{Analytical application of the prepared electrode for propranolol electrooxidation}

As outlined in the "Introduction" section, propranolol plays really an important role in human life so its accurate quantification is justified. Both a decrease in the overpotential of oxidation and an increase in the current density observed 
a)

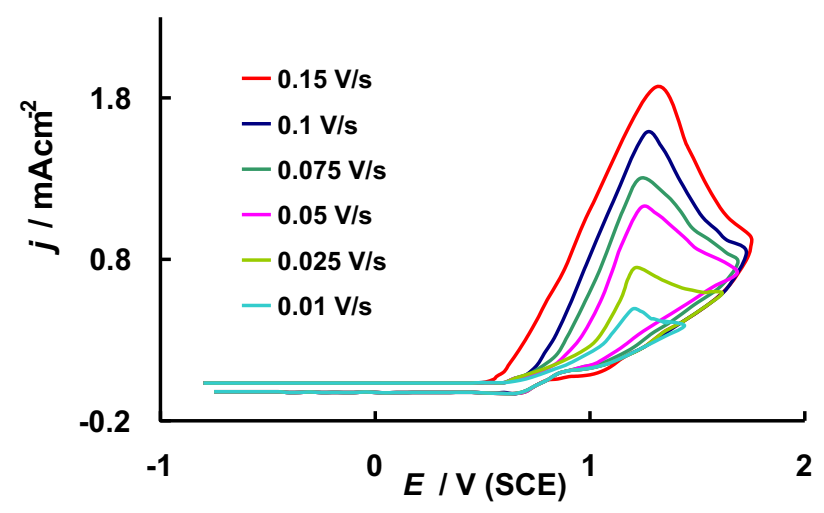

b)

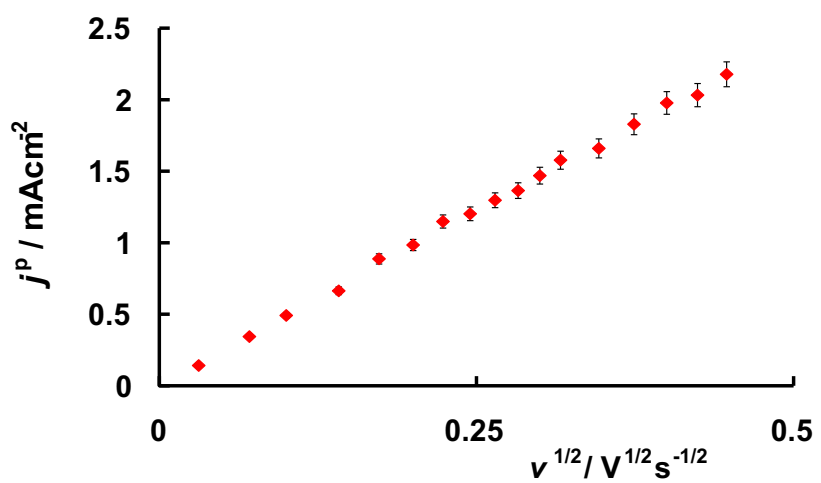

c)

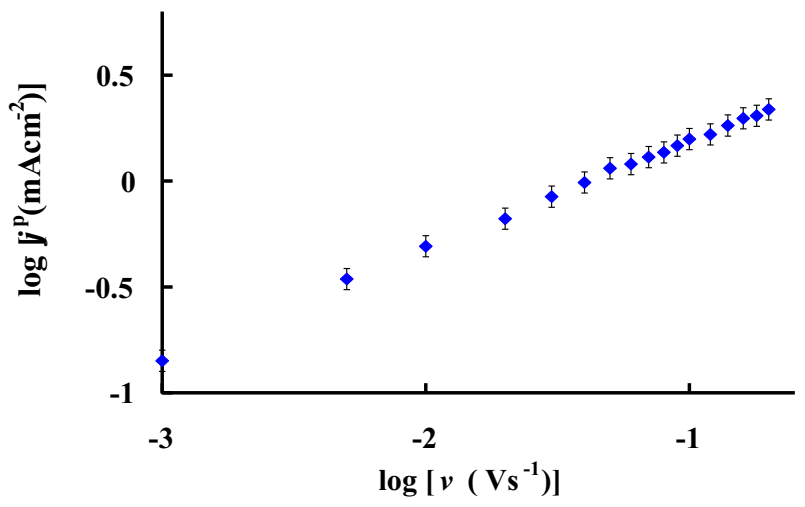

Fig. 5 a Cyclic voltammetric responses of 3D Au-NPs-Au in a phosphate buffer containing $0.002 \mathrm{mM}$ propranolol at different scan rates. b The variation of anodic peak current density versus square root of scan rate varied 0.001 to $1 \mathrm{~V} \mathrm{~s}^{-1}$ for $0.002 \mathrm{mM}$ propranolol in phosphate buffer. $\mathrm{c}$ The variation of the logarithm anodic peak current density versus the logarithm of scan rate varied from 0.001 to $2 \mathrm{~V} \mathrm{~s}^{-1}$ for $0.002 \mathrm{mM}$ propranolol in phosphate buffer

during propranolol oxidation at the 3D Au-NPs-Au electrode, without a doubt, make the modified sensor suitable for analytical application. The analytical sensitivity of the 3D AuNPs-Au electrode toward propranolol quantification was determined by using DPV (the differential pulse voltammetry) method with the following parameters: the step potential:
$4 \mathrm{mV}$, the pulse wide $50 \mathrm{~ms}$, the pulse period $200 \mathrm{~ms}$ and the pulse amplitude $10 \mathrm{mV}$. The solute concentration has been changed in range from 0.0001 to $0.035 \mathrm{mM}$. The differential pulse voltammograms (DVPs) recorded on 3D Au-NPs-Au for selected concentrations of propranolol from the above range are presented in Fig. 6a. As follows from these data, a direct correlation between increasing propranolol concentration in the phosphate buffer and increasing current density on the recorded DVPs is well pronounced.

As follows from Fig. 6b, the linearity between the current peak density $j^{p}$ corresponding to the electrooxidation of propranolol and its concentration in supporting electrolyte solution is satisfied in the concentration interval from 0.0001 to $0.02 \mathrm{mM}$. For propranolol, the following linear regression equation is satisfied: $j_{\mathrm{p}}\left[\mathrm{mA} / \mathrm{cm}^{2}\right]=(412 \pm 17) \cdot 10^{-3}+(570 \pm$ 11) $c_{\text {PROP }}[\mathrm{mM}] ;\left(R^{2}=0.999 ; n=28\right)$. The detection limit $c_{\mathrm{L}}$, calculated from the formula recommended by IUPAC [62]: $c_{L}=3 S_{b} / S$ (where 3 means the numerical constant, $S_{\mathrm{b}}$, is the standard deviation of the current density in the supporting electrolyte solution, and $S$ is the slope of $j_{\mathrm{p}}$
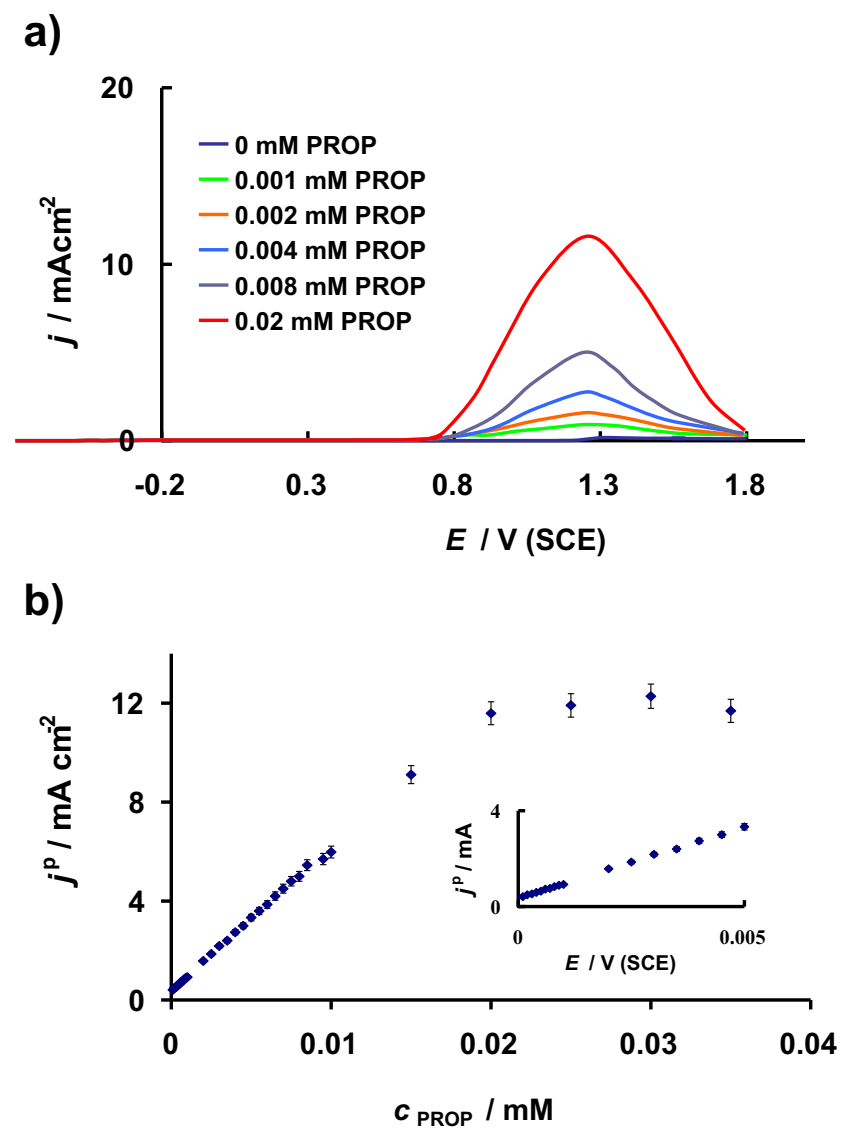

Fig. 6 a Differential pulse voltammograms recorded on the 3D Au-NPsAu gold electrode (DVP parameters: the step potential: $4 \mathrm{mV}$, the pulse wide $50 \mathrm{~ms}$, the pulse period $200 \mathrm{~ms}$, and the pulse amplitude $10 \mathrm{mV}$ ) during electrooxidation of different concentrations of propranolol in $70 \mathrm{mM}$ phosphate buffer, $\mathrm{pH}$ 7.4. b Analysis of $j-c_{\mathrm{PROP}}$. Insert: For clarity, analysis of $j-c_{\mathrm{PROP}}$ in the narrow propranolol concentration ( 0.0001 to $0.005 \mathrm{mM})$ 
Table 1 Determination of propranolol in samples obtained by dissolving the propranolol tablet or its solution for injection in the simulated body fluid

\begin{tabular}{lllll}
\hline $\begin{array}{l}\text { Sample } \\
\text { number }\end{array}$ & $\begin{array}{l}\text { Nominal } \\
\text { content of } \\
\text { propranolol } \\
{[\mathrm{mM}]^{\mathrm{a}}}\end{array}$ & $\begin{array}{l}\text { Propranolol } \\
\text { concentration } \\
\text { fund }[\mathrm{mM}]^{\mathrm{a}}\end{array}$ & $\begin{array}{l}\text { Nominal } \\
\text { content of } \\
\text { propranolol } \\
{[\mathrm{mM}]^{\mathrm{b}}}\end{array}$ & $\begin{array}{l}\text { Propranolol } \\
\text { concentration } \\
\text { fund }[\mathrm{mM}]^{\mathrm{b}}\end{array}$ \\
\hline 1 & $2 \times 10^{-3}$ & $2.1 \times 10^{-3}$ & $3.86 \times 10^{-3}$ & $3.76 \times 10^{-3}$ \\
2 & $4 \times 10^{-3}$ & $3.98 \times 10^{-3}$ & $3.86 \times 10^{-3}$ & $3.91 \times 10^{-3}$ \\
3 & $6 \times 10^{-3}$ & $6.05 \times 10^{-3}$ & $3.86 \times 10^{-3}$ & $3.95 \times 10^{-3}$ \\
$\begin{array}{l}\text { R.S.D. (\%) } \\
\text { Recovery } \\
(\%)\end{array}$ & & $2.33 \%$ & & $2.03 \%$ \\
\hline
\end{tabular}

a The source of propranolol - a tablet

${ }^{b}$ The source of propranolol — a solution for injection

$c_{\text {PROP }}$ linear dependence, respectively), was equal $6.75 \times$ $10^{-5} \mathrm{mM}$. There is no doubt that the 3D Au-NPs-Au modified electrode is suitable for precise determination of propranolol in buffered solution of physiological $\mathrm{pH}$. The $c_{\mathrm{L}}$ value and linearity range of propranolol quantification obtained with the modified electrode prepared in this work were compared with the analogous parameters obtained on the other electrodes described in literature [27, 31-43]; it can be concluded that in the vast majority of tested electrodes, both the linearity and the $c_{\mathrm{L}}$ value were better when 3D Au-NPs-Au electrode was used (see the electronic supplementary material, Table S1). This observations mean that both the selection of the 3D Au-NPs-Au electrode and methods used for the propranolol testing were correct and reasonable.

\section{Real sample analysis}

The practical application of the prepared hybrid inorganic/ organic voltammetric sensor for quantitative determination of propranolol was tested by differential pulse voltammetry (DVP) using the calibration method [63]. For this purpose, different volumes of the propranolol solution prepared by using commercial pharmaceutical formulations were diluted with the simulated body fluid (see the "Experimental" section). For each studied propranolol sample at an exact concentration, the measurements were repeated three times. Table 1 presents the arithmetic average values of concentrations obtained from the conduced tests. There is no doubt that both the relative standard deviations (R.S.D.) and the recovery ranges of propranolol determination in the prepared samples proved that both the voltammetric sensor prepared and the proposed method of concentration determination could be useful tool for the determination of propranolol in bioanalytical analysis.

\section{Interfering analysis}

Electrochemical quantitative determination of different drugs in real samples is in most cases affected by interference of some biogenic compounds like dopamine, ascorbic acid or uric acid. According to literature, the presence of both AA and UA in the mixture with DA has no effect on the simultaneous quantitative detection of these compounds when measurements are carried out on modified electrodes, regardless of the type of conductive material used in the electrochemical sensor. For example, such results were observed on different carbon, or noble metal electrodes modified with organic sulfur compounds and gold nanoparticles or on reduced graphene oxide modified with bimetallic alloyed nanoparticles [64-68]. In this study, the effect of possible interference of uric acid, ascorbic acid, and dopamine on propranolol determination was examined. Comparison of the $\mathrm{p} K_{\mathrm{a}}$ values of uric acid $\left(\mathrm{p} K_{\mathrm{a}}=5.4\right)$, ascorbic acid $\left(\mathrm{p} K_{\mathrm{a}}=4.1\right)$, dopamine $\left(\mathrm{p} K_{\mathrm{a}}=\right.$ 8.87), and propranolol ( $\left.K_{\mathrm{a}}=9.45\right)$ (www.Reaxys.com) [68] shows that the $\mathrm{p} K_{\mathrm{a}}$ value of propranolol is higher than that of DA, UA, and AA so the peaks of the tested four-component mixture are separated along the potential axis as a result of electrostatic interactions. The results of measurements performed in the four-component mixture (propranolol, uric acid, ascorbic acid, and dopamine) are listed in Table 2. The data collected in Table 2 unquestionably prove that the sensor proposed in this work can be successfully used for the determination of propranolol in the presence of the abovementioned

Table 2 Determination of propranolol (1), uric acid (2), ascorbic acid (3), and dopamine (4) in the four-component mixture in the SBF solution

Sample number Nominal content of given compound in the four-component mixture $[\mathrm{mM}]$

\begin{tabular}{llll}
\hline 1 & 2 & 3 & 4
\end{tabular}

\begin{tabular}{llllll} 
& 1 & 2 & 3 & 4 \\
\hline 1 & $1 \times 10^{-3}$ & $5 \times 10^{-2}$ & $5 \times 10^{-2}$ & $1 \times 10^{-3}$ & 1 \\
2 & $1 \times 10^{-2}$ & $5 \times 10^{-2}$ & $5 \times 10^{-2}$ & $1 \times 10^{-2}$ & 2 \\
3 & $1 \times 10^{-2}$ & $5 \times 10^{-2}$ & $5 \times 10^{-2}$ & $1 \times 10^{-2}$ & 3
\end{tabular}

R.S.D. $(\%)$

Recovery $(\%)$
Sample Concentration fund of given compound in the four-component number mixture $[\mathrm{mM}]$

\begin{tabular}{llll}
\hline 1 & 2 & 3 & 4 \\
\hline $0.99 \times 10^{-3}$ & $5.1 \times 10^{-2}$ & $4.97 \times 10^{-2}$ & $1.05 \times 10^{-3}$ \\
$0.98 \times 10^{-3}$ & $5.2 \times 10^{-2}$ & $5.04 \times 10^{-2}$ & $0.96 \times 10^{-2}$ \\
$1.01 \times 10^{-3}$ & $4.89 \times 10^{-2}$ & $4 \times 96 \times 10^{-2}$ & $0.98 \times 10^{-2}$ \\
$1.33 \%$ & $2.01 \%$ & $2.7 \%$ & $3.6 \%$ \\
$98-101 \%$ & $98-102 \%$ & $99-102 \%$ & $96-106 \%$ \\
\hline
\end{tabular}

1-propranolol; 2-uric acid; 3-ascorbic acid; 4-dopamine 
biogenic interfering compounds. The obtained recovery and relative standard deviation are very good, indicating the efficiency of the tested sensor. Moreover, because these measurements were made in the SBF solution which has very close content to the human body fluid [46], the prepared electrochemical sensor is much promising for reliable and sensitive application in medical and pharmacology analysis.

\section{Reproducibility and stability of the 3D-Au-NPs-Au prepared sensor}

The reproducibility of the 3D Au-NPs-Au sensor was checked in the experiment in which two prepared in the same way modified 3D Au-NPs-Au electrodes were examined. For each of them, cyclic voltammetric curves $(\mathrm{CVs})$ were recorded with $\mathrm{d} E / \mathrm{d} t=0.1 \mathrm{~V} \mathrm{~s}^{-1}$ in $0.07 \mathrm{mM}$ phosphate buffer solution with addition of $0.002 \mathrm{mM}$ of propranolol. The relative standard deviation (R.D.S.) was about $2.8 \%$ and $2.9 \%$ after 30 successive CVs scans for two independently tested modified electrodes, respectively. This result indicates that the prepared sensor ensures excellent reproducibility. The stability of the 3D Au-NPs-Au prepared sensor was tested also for two sensors prepared in the same way. For 4 weeks (5 times a week), 5 CVs were recorded with $\mathrm{d} E / \mathrm{d} t=0.1 \mathrm{~V} \mathrm{~s}^{-1}$ in $0.07 \mathrm{mM}$ buffer phosphate solution with addition of $0.002 \mathrm{mM}$ of propranolol. After each daily test, both modified electrodes tested were rinsed with deionized water and dried. Between the measurements, the tested sensors were stored in empty glass tubes. After 4 weeks of the stability testing experiment, the current densities recorded with these two tested electrodes retained about $96 \%$ of their initial values. The results have shown that the 3D Au-NPs-Au prepared sensor had good stability.

\section{Conclusion}

A hybrid nanocomposite inorganic/organic modified gold template has been presented. The modifying agents were gold nanoparticles, 4-mercaptobutyric acid, and cysteamine. The proposed method of preparation of the novel modified material is fast simple and green, e.g., does not need using toxic compounds and solutions. The resulting 3D catalyst was used as a conducting material in a voltammetric sensor for electrooxidation and quantification of propranolol - the effective antagonist of $\beta$-adrenergic receptors. The prepared sensor displays good sensitivity and stability. Using the differential pulse voltammetry for propranolol quantification, the linear range between 0.0001 and $0.02 \mathrm{mM}$ was found with a detection limit of $6.75 \times 10^{-5} \mathrm{mM}$. Moreover, it has been established that propranolol can be determined in the presence of some biogenic compounds like dopamine, ascorbic acid, or uric acid without any interferences. All these properties are promising for application of the 3D Au-NPs-Au both in clinical analysis, quality control and routine determination of propranolol in pharmaceutical formulation. The results obtained on prepared modified electrode are in agreement with the common tendency observed in the last decades that in electrochemical sensing of different pharmaceutical drugs, indeed the modified electrodes are more useful as compared to the unmodified electrodes.

Acknowledgments Much thanks are due to Ms. Adrianna Chojna for the skillful technical assistance in measurements.

Funding information This study received financial support from the Polish Ministry of Science and High Education.

\section{Compliance with ethical standards}

Conflict of interest The author declares that there is no conflict of interest.

Open Access This article is distributed under the terms of the Creative Commons Attribution 4.0 International License (http:// creativecommons.org/licenses/by/4.0/), which permits unrestricted use, distribution, and reproduction in any medium, provided you give appropriate credit to the original author(s) and the source, provide a link to the Creative Commons license, and indicate if changes were made.

\section{References}

1. Podlewski JK, Chwalibogowska-Podlewska A (2007) An encyclopedia of pharmacy practice and clinical pharmacy. In: Split Trading (ed) 18th edn. Warsaw

2. Soriano JB, Hoes AW, Meems L, Grobbee DE (1997) Increased survival with b-blockers: importance of ancillary properties. Prog Cardiovasc Dis 39:445-456

3. Emilien G, Maloteaux JM (1998) Current therapeutic uses and potential of beta-adrenoceptor agonists and antagonists. Eur J Clin Pharmacol 53:389-404

4. Pharmindex (2012) Drugs compendium. UBM Medica (Poland)

5. Steenen SA, van Wijk AJ, van der Heijden GJ, van Westrhenen R, de Lange J, de Jongh A (2015) Propranolol for the treatment of anxiety disorders: systematic review and meta-analysis. J Psychopharmacol 30:128-139

6. Steptoe A, Malik F, Pay C, Pearson P, Price C, Win Z (1995) The impact of stage fright on student actors. Br J Psychol 86:27-39

7. El-Emam AA, Belal FF, Moustafa MA, El-Ashry SM, El-Sherbiny DT, Hansen SH (2003) Spectrophotometric determination of propranolol in formulations via oxidative coupling with 3methylbenzothiazoline-2-one hydrazone. Il Farmaco 58:1179-1186

8. Gowda BG, Seetharamappa J, Melwanki MB (2002) Indirect spectrophotometric determination of propranolol hydrochloride and piroxicam in pure and pharmaceutical formulations. Anal Sci 18: 671-674

9. Zhang F, Du YX, Ye BF, Li P (2007) Study on the interaction between the chiral drug of propranolol and $\alpha 1$-acid glycoprotein by fluorescence spectrophotometry. J Photochem Photobiol B 86: 246-225

10. Muñoz de la Peña A, Salinas F, Durán MS (1991) Simultaneous determination of propranolol and hydralazine by derivative synchronous spectrofluorimetry. Anal Chim Acta 255:317-323 
11. Pérez RT, Martínez-Lozano C, Tomás V, Carpena J (1998) Simultaneous determination of propranolol and pindolol by synchronous spectrofluorimetry. Talanta 45:969-976

12. Ramesh KC, Gowda BG, Seetharamappa J, Keshavayya J (2003) Indirect spectrofluorimetric determination of piroxicam and propranolol hydrochloride in bulk and pharmaceutical preparations. J Anal Chem 58:933-936

13. El-Ries MA, Abou Attia FM, Ibrahim SA (2000) AAS and spectrophotometric determination of propranolol $\mathrm{HCl}$ and metoprolol tartrate. J Pharm Biomed Anal 24:179-187

14. Khalil S, Borham N (2000) Indirect atomic absorption spectrometric determination of pindolol, propranolol and levamisole hydrochlorides based on formation of ion-associates with ammonium reineckate and sodium cobaltnitrite. J Pharm Biomed Anal 22: 235-240

15. Gotardo MA, Tognolli JO, Pezza HR, Pezza L (2008) Detection of propranolol in pharmaceutical formulations by diffuse reflectance spectroscopy. Spectroschim Acta A 69:1103-1109

16. Townshend A, Murillo Pulgarin JA, Al Padro MT (2003) Flow injection-chemiluminescence determination of propranolol in pharmaceutical preparations. Anal Chim Acta 488:81-88

17. Tsogas GZ, Stergiou DV, Vlessidis AG, Evmiridis NP (2005) Development of a sensitive flow injection-chemiluminescence detection method for the indirect determination of propranolol. Anal Chim Acta 541:149-155

18. Qi Y, Xiu F-R (2016) Sensitive and rapid chemiluminescence detection of propranolol based on effect of surface charge of gold nanoparticles. J Lumin 171:238-245

19. Rapado-Martínez I, García-Alvarez-Coque MC, VillanuevaCamañas RM (1997) Liquid chromatographic procedure for the evaluation of $\beta$-blockers in pharmaceuticals using hybrid micellar mobile phases. J Chromatogr A 765:221-231

20. El-Saharty YS (2003) Simultaneous high-performance liquid chromatographic assay of furosemide and propranolol HCL and its application in a pharmacokinetic study. J Pharm Biomed Anal 33: 699-709

21. Partani P, Modhave Y, Gurule S, Khuroo A, Monif T (2009) Simultaneous determination of propranolol and 4hydroxypropranolol in human plasma by solid phase extraction and liquid chromatography/electrospray tandem mass spectrometry. J Pharm Biomed Anal 50:966-976

22. Idowu OS, Adegoke OA, Olaniyi AA (2004) Colorimetric assay of propranolol tablets by derivatization: novel application of diazotized 4-amino-3,5-dinitrobenzoic acid (ADBA). J AOAC Int 87: 573-578

23. Pathak VN, Shukla MSR, Shuklahukla IC (1982) Direct titrimetric determination of the antihypertensive drugs methyldopa and propranolol in pharmaceutical preparations. Analyst 107:086-1087

24. Abassi UM, Chand F, Bhanger MI, Memon SA (1986) A rapid method for the determination of some antihypertensive and antipyretic drugs by thermometric titrimetry. Talanta 33:173-175

25. McMurry J (2005) Organic chemistry. National Scientific Publishers, Warsaw

26. Bard AJ, Faulkner LK (2001) Electrochemical methods: fundamentals and applications. Wiley, New York

27. El-Ries MA, Abou-Sekkina MM, Wassel AA (2002) Polarographic determination of propranolol in pharmaceutical formulation. J Pharm Biomed Anal 30:837-842

28. Radi A, Wassel AA, El-Ries MA (2004) Adsorptive behavior and voltammetric analysis of propranolol at a carbon paste electrode. Chem Anal 49:51-58

29. Ambrosi A, Antiochia R, Campanella L, Dragone R, Lavagnini I (2005) Electrochemical determination of pharmaceuticals in spiked water samples. J Hazard Mater 122:219-225
30. Bishop E, Hussein W (1984) Electroanalytical studies of betaadrenergic blocking agents; $N$-isopropylethanolamine derivatives; procainamide. Analyst 109:65-71

31. Sartori ER, Medeiros RA, Rocha-Filho RC, Fatibello-Filho O (2010) Square-wave voltammetric determination of propranolol and atenolol in pharmaceuticals using a boron-doped diamond electrode. Talanta 81:1418-1124

32. dos Santos SX, Cavalheiro ÉTG, Brett CMA (2010) Analytical potentialities of carbon nanotube/silicone rubber composite electrodes: determination of propranolol. Electroanalysis 22:27762783

33. dos Santos SX, Cavalheiro ÉTG (2012) Evaluation of the potentialities of a carbon nanotubes/silicone rubber composite electrode in the determination of hydrochlorothiazide. Anal Lett 45:1454-1466

34. Kun Z, Shuai Y, Dongmei T, Yuyang Z (2013) Electrochemical behavior of propanol hydrochloride in neutral solution on calixarene/multi-walled carbon nanotubes modified glassy carbon electrode. J Electroanal Chem 709:99-105

35. Kun Z, Yi H, Chengyun Z, Yua Y, Shuliang Z, Yuyang Z (2012) Electrochemical behavior of propanol hydrochloride in neutral solution on platinum nanoparticles doped multi walled carbon nanotubes modified glassy carbon electrode. Electrochim Acta 80:405412

36. Kun Z, Hongtao C, Yue Y, Zhihong B, Fangzheng L, Sanming L (2015) Platinum nanoparticle-doped multiwalled carbon-nanotubemodified glassy carbon electrode as a sensor for simultaneous determination of atenolol and propranolol in neutral solution. Ionics 21:1129-1140

37. Oliveira GG, Azzi DC, Vicentini FC, Sartori ER, Fatibello-Filho O (2013) Voltammetric determination of verapamil and propranolol using a glassy carbon electrode modified with functionalized multiwalled carbonnanotubes within a poly (allylamine hydrochloride) film. J Electroanal Chem 708:73-79

38. Gaichore RR, Srivastava AK (2014) Electrocatalytic determination of propranolol hydrochlorideat carbon paste electrode based on multiwalled carbon-nanotubesand c-cyclodextrin. J Incl Phenom Macrocycl Chem 78:195-206

39. Lourencao BC, Silva TA, Fatibello-Filho O, Swain GM (2014) Voltammetric studies of propranolol and hydrochlorothiazide oxidation in standard and synthetic biological fluids using a nitrogencontaining tetrahedral amorphous carbon (ta-C:N) electrode. Electrochim Acta 143:398-406

40. Raj M, Gupta P, Goyal RN (2016) Poly-melamine film modified sensor for the sensitive and selective determination of propranolol, a $\beta$-blocker in biological fluids. J Electrochem Soc 163:H388-H394

41. Gupta P, Yadav SK, Agrawal B, Goyal RN (2014) A novel graphene and conductive polymer modified pyrolyticgraphite sensor for determination of propranolol in biological fluids. Sensors Actuators B Chem 204:791-798

42. Mohammadizadeh N, Mohammadi SZ, Kaykhai M (2017) Highly sensitive amperometric detection of propranolol using graphite screen printed electrode modified with zirconium dioxide nanoparticles. Anal Bioanal Electrochem 9:277-285

43. Santos AM, Wong A, Fatibello-Filho O (2018) Simultaneous determination of salbutamol and propranolol in biological fluid samples using an electrochemical sensor based on functionalized graphene, ionic liquid and silver nanoparticles. J Electroanal Chem 824:1-8

44. Rurack K, Martínez-Máñez R (2010) The supramolecular chemistry of organic-inorganic hybrid materials. Wiley, Hoboken

45. Turkevich J, Stevenson PC, Hillier J (1951) A study of the nucleation and growth processes in the synthesis of colloidal gold. Discuss Faraday Soc 11:55-75

46. Kokubo T (1991) Bioactive glass ceramics: properties and applications. Biomaterials 12:155-163 
47. Łuczak T (2008) Electrochemical behaviour of benzylamine, 2phenylethylamine and 4-hyroxy-phenylethylamine at gold. A comparative study. J Appl Electrochem 38:43-50

48. Meier A, Uhlendorf I, Meissner D (1995) Electrochemical features of electrodes modified with multiple nano contacts (MNCs) from colloidal noble metal particles. Electrochim Acta 40:1523-1535

49. Sellers H, Ulman A, Shnidman Y, Eilers JE (1993) Structure and binding of alkanethiolates on gold and silver surfaces: implications for self-assembled monolayers. J Am Chem Soc 115:9389-9401

50. Ulman A (1996) Formation and structure of self-assembled monolayers. Chem Rev 96:1533-1554

51. Dodero G, De Michieli L, Cavalleri O, Rolandi R, Olivieri L, Dacca A, Parodi R (2000) L-cysteine chemisorption on gold: an XPS and STM study. Colloids Surf A 175:121-128

52. Wang L, Bai J, Huang P, Wang H, Zhang L, Zhao Y (2006) Selfassembly of gold nanoparticles for the voltammetric sensing of epinephrine. Electrochem Commun 8:1035-1040

53. Paik W-K, Eu S, Lee K, Chon S, Kim (2000) Electrochemical reactions in adsorption of organosulfur molecules on gold and silver: potential dependent adsorption. Langmuir 16:10198-10205

54. Chon S, W-k P (2001) Adsorption of self-assembling sulfur compounds through electrochemical reactions; effects of potential, acid and oxidizing agents. Phys Chem Chem Phys 3:3405-3410

55. Liu S-F, Li X-H, Li Y-C, Li Y-F, Li J-R, Jiang L (2005) The influence of gold nanoparticles modified electrode on the structure of marcaptopropionic acid self-assembly monolayer. Electrochim Acta 51:427-431

56. Zhang J, Oyama M (2007) Electrocatalytic activity of threedimensional monolayer of 3-mercaptopropionic acid assembled on gold nanoparticles arrays. Electrochem Commun 9:459-464

57. Leopold MC, Black JA, Bowden EF (2002) Influence of gold topography on carboxylic acid terminated self-assembled monolayers. Langmuir 18:978-980

58. Finot MO, McDermott MT (2000) Characterization of $n$ alkanethiolate monolayers adsorbed to electrochemically deposited gold nanocrystals on glassy carbon electrodes. J Electroanal Chem 488:125-132

59. Łuczak T (2008) Preparation and characterization of the dopamine film electrochemically deposited on a gold template and its applications for dopamine sensing. Electrochim Acta 53:5725-5731
60. Lund H, Hammerich O (1991) Organic electrochemistry, 4th edn. Marcel Dekker Inc, New York

61. Kisza A (2001) Electrochemistry II. Technical Scientific Publishers, Warsaw

62. Analytical Methods (1987) Committee, recommendation for definition, estimation and use of the detection limit. Analyst 112:199204

63. Szczepaniak W (2017) Instrumental methods in chemical analysis. Scientific Publishers PWN, Warsaw

64. Łuczak T, Osińska M (2017) New self-assembled layers composed with gold nanoparticles, cysteamine and dihydrolipoic acid deposited on bare gold template for highly sensitive and selective simultaneous sensing of dopamine in the presence of interfering ascorbic and uric acids. J Solid State Electrochem 21:747-758

65. Łuczak T, Beltowska-Brzezinska M (2011) Gold electrodes modified with gold nanoparticles and thiol compounds for electrochemical sensing of dopamine alone and in the presence of potential interferents. A comparative study. Microchim Acta 174:19-30

66. Chen LX, Zheng JN, Wang AJ, Wu LJ, Chen J, Feng JJ (2015) Facile synthesis of porous bimetallic alloyed PdAg nanoflowers supported on reduced graphene oxide for simultaneous detection of ascorbic acid, dopamine, and uric acid. Analyst 140:3183-3192

67. Reddy YVM, Sravani B, Łuczak T, Osińska M, Maseed H, Ragavendra P, Subramanyam Sarma L, Srikanthand VVSS, Madhavi G (2018) An ultra-sensitive electrochemical sensor sensor for the detection of acetaminophen in the presence of etilefrine using bimetallic $\mathrm{Pd}-\mathrm{Ag} /$ reduced graphene oxide nanocomposites. New J Chem 42:3137-3146

68. Osol A, Hoover JE (1975) Pharmaceutical Sciences In Remington's, 15th edn. Mack Publishing Co, Easton, p 835

Publisher's note Springer Nature remains neutral with regard to jurisdictional claims in published maps and institutional affiliations. 